\title{
ГЕОИНФОРМАЦИОННЫЙ АНАЛИЗ РАСПОЛОЖЕНИЯ ЗОН ВЕРОЯТНОГО ВОЗНИКНОВЕНИЯ ЧРЕЗВЫЧАЙНЫХ СИТУАЦИЙ НА ТЕРРИТОРИИ ГОРОДА ИРКУТСКА
}

\section{Мария Николаевна Бельц}

Сибирский государственный университет геосистем и технологий, 630108, Россия, г. Новосибирск, ул. Плахотного, 10, обучающийся, тел. (923)144-86-62, e-mail: marybelts98@gmail.com

\section{Алексей Викторович Дубровский}

Сибирский государственный университет геосистем и технологий, 630108, Россия, г. Новосибирск, ул. Плахотного, 10, кандидат технических наук, зав. кафедрой кадастра и территориального планирования, тел. (383)361-01-09, e-mail: avd5@ssga.ru

В статье рассмотрены чрезвычайнее ситуации, которые могут оказать влияние на стоимость объектов недвижимости, выполнен геоинформационный анализ расположения зон вероятного возникновения чрезвычайных ситуаций на территории города Иркутск, на основе анализа сформирована общая схема потенциально опасных территорий города. При выполнении работ используется геоинформационная система с картой-схемой территории города Иркутск, а также План гражданской обороны чрезвычайных ситуаций города Иркутск, который опирается на требования СНиП 2.01.51-90 «Инженерно-технические мероприятия гражданской обороны».

Ключевые слова: чрезвычайная ситуация (ЧС), геоинформационный анализ, зона вероятного возникновения ЧС, территория города, кадастровая стоимость, потенциально опасная территория

\section{GIS ANALYSIS FOR THE LOCATION OF ZONES OF PROBABLE OCCURRENCE OF EMERGENCY SITUATIONS ON THE TERRITORY OF THE CITY OF IRKUTSK}

\section{Maria N. Belts}

Siberian State University of Geosystems and Technologies, 10, Plakhotnogo St., Novosibirsk, 630108, Russia, Student, phone: (923)144-86-62, e-mail: marybelts98@gmail.com

\section{Alexey V. Dubrovsky}

Siberian State University of Geosystems and Technologies, 10, Plakhotnogo St., Novosibirsk, 630108, Russia, Ph. D., Head of the Department of Cadastre and Territorial Planning, phone: (383)361-01-09, e-mail: avd5@ssga.ru

The article considers emergency situations that may affect the value of real estate objects, a geoinformation analysis of the location of zones of probable occurrence of emergencies on the territory of the city of Irkutsk was performed, and based on the analysis, a General scheme of potentially dangerous territories of the city is formed. When performing the work, a geo-information system with a map of the territory of the city of Irkutsk is used, as well as a civil defense plan for emergency situations in the city of Irkutsk, which is based on the requirements of SNiP 2.01.51-90 "Civil Defense Engineering Measures".

Keywords: emergency situation (ES), geoinformation analysis, zone of probable occurrence of an emergency, territory of the city, cadastral value, potentially dangerous territory 
Чрезвычайная ситуация (ЧС) - обстоятельства на определенной территории, сложившиеся в результате аварии, катастрофы, опасного природного явления, распространения заболевания, повлекшие за собой человеческие жертвы или представляющие опасность для жизни и здоровья граждан, а также причинение значительного материального ущерба.

Предотвращение чрезвычайной ситуации - комплекс мероприятий, направленных на уменьшение риска возникновения чрезвычайной ситуации, а также сохранение здоровья людям, снижение размеров материального и экологического ущерба.

Данный комплекс включает в себя:

- мониторинг и прогнозирование;

- рациональное размещение потенциально опасных объектов;

- совершенствование технологических процессов и повышение квалификации работников;

- информирование населения о потенциально опасных зонах и объектах и многое другое.

В работе рассмотрены чрезвычайные ситуации, которые могут повлиять на первоначальные потребительские качества объектов недвижимости на территории города и на основе этого создали геоинформационную модель зон чрезвычайных ситуаций:

1. Большинство городов располагается около рек, поэтому риск затопления территорий актуален для многих из них. На рисунке представлена зона возможного затопления в случае прорыва плотины. По предварительной оценке, зона затопления составит 129,12 км² (рис. 1).
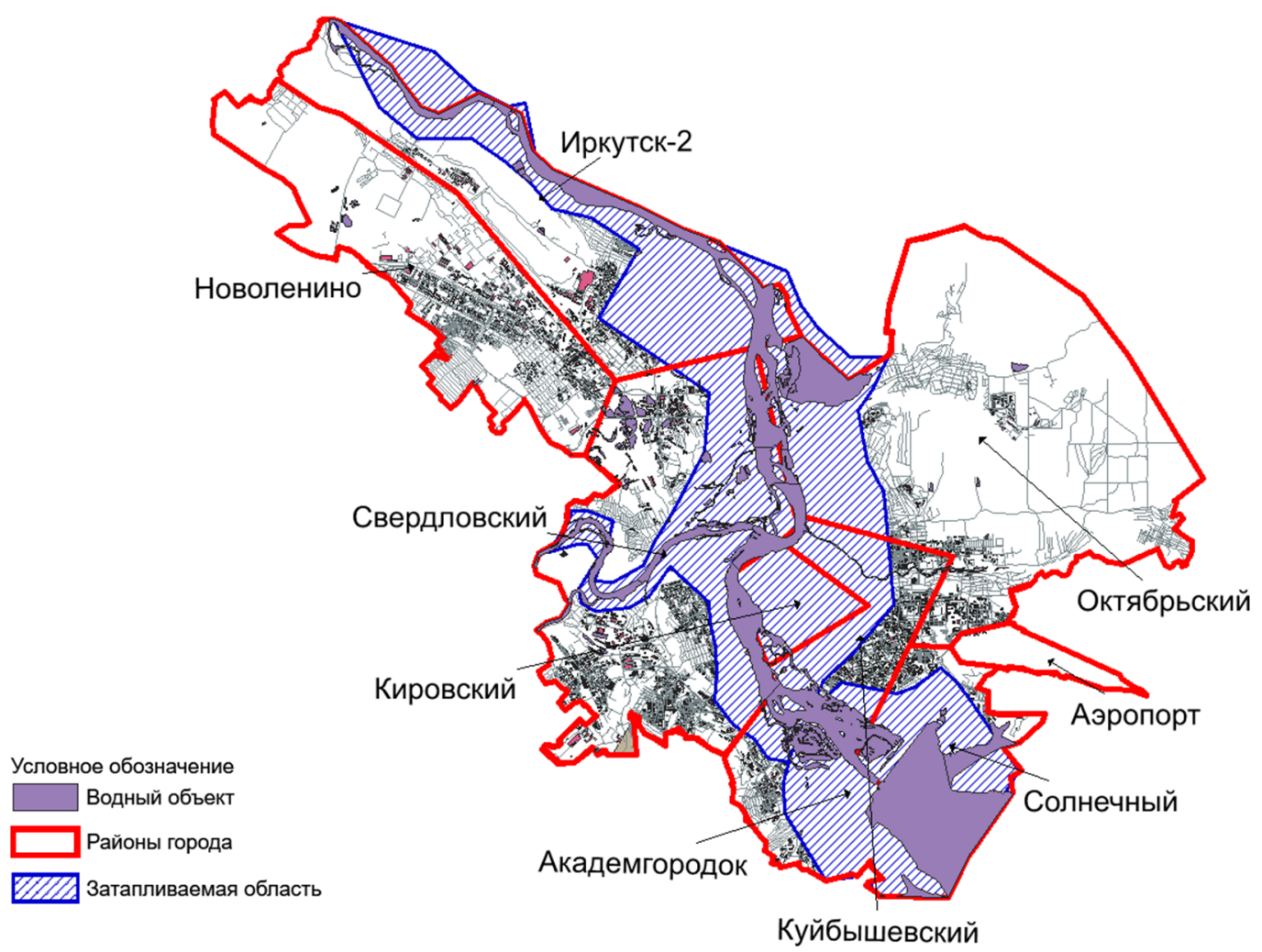

Рис. 1. Территория, затапливаемая в случае прорыва плотины ГЭС 
2. Аварии на потенциально опасных объектах, т.е. на химически опасных и взрывопожарных объектах, несут риск химического заражения. В данном случае опасным веществом выступает - хлор и аммиак. Зона поражения в случае химической опасности 2,5 км; в случае аварии на взрывопожарных объектах, радиус 0,5 км (рис. 2).
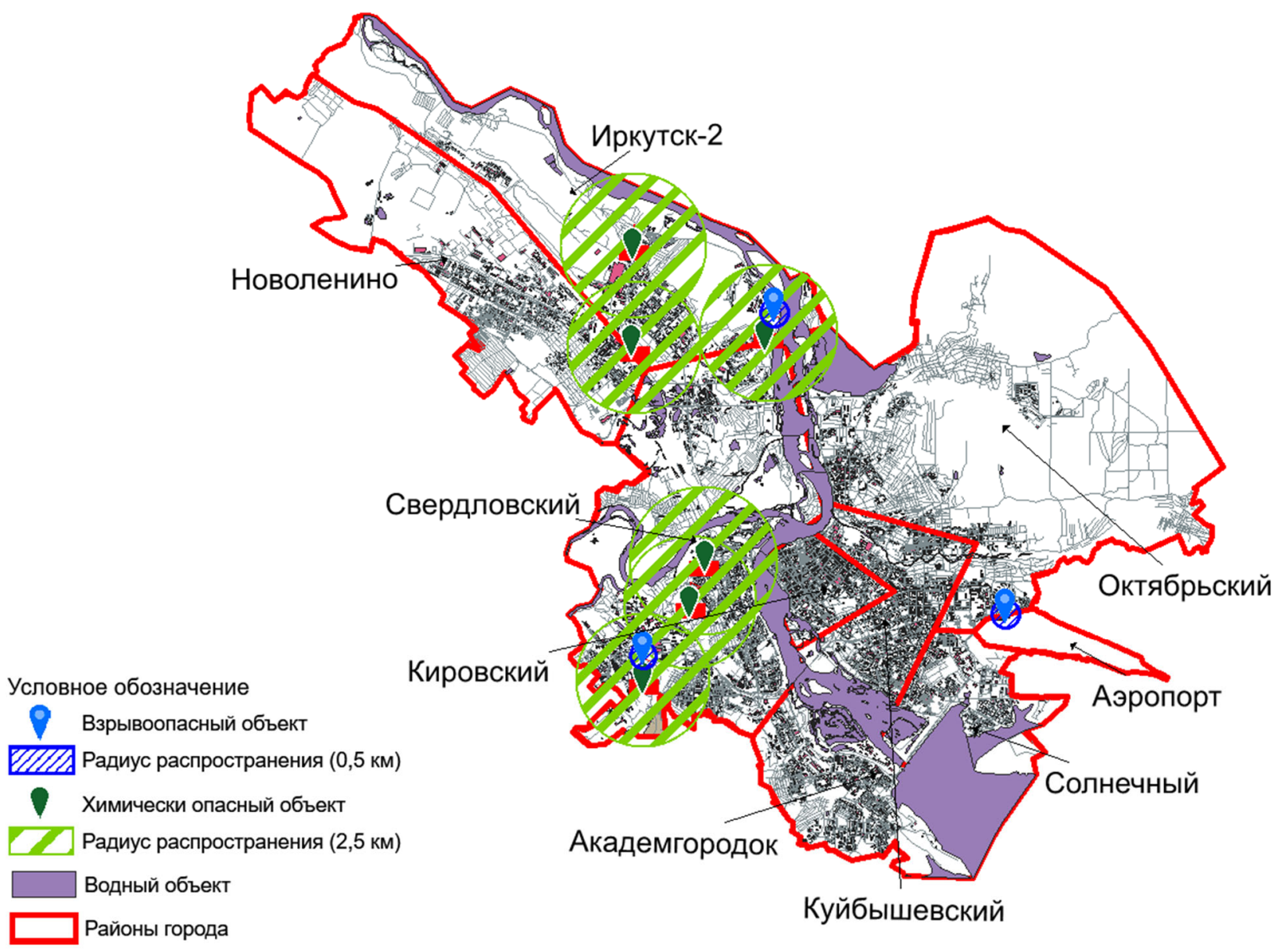

Рис. 2. Территория, подверженная последствиям аварии на потенциально опасных объектах

3. Иркутск является крупнейшим железнодорожным узлом Сибири, здесь расположено несколько заводов, использующих опасные вещества, перевозят их железнодорожным или автомобильным транспортом. При авариях на транспортных магистралях, связанных с транспортировкой опасных веществ, стойкость химических веществ в воздухе остается в среднем от 1,5 до 3 часов, радиус загрязнения 500 м. Мы выделили наиболее крупные и опасные магистрали, данные приведены на рис. 3.

4. Берега Иркутского водохранилища, расположенные на равнинных и степных зонах - наименее устойчивые типы ландшафта, поэтому возможен риск размыва берегов. Скорость отступания берегов от 1 до 3 метров в год. Процесс размыва берегов водохранилища достаточно продолжительный, на рисунке показано какие объекты наиболее подвержены риску разрушения в течение 10 лет - несколько объектов недвижимости в Свердловском районе (рис. 4). 


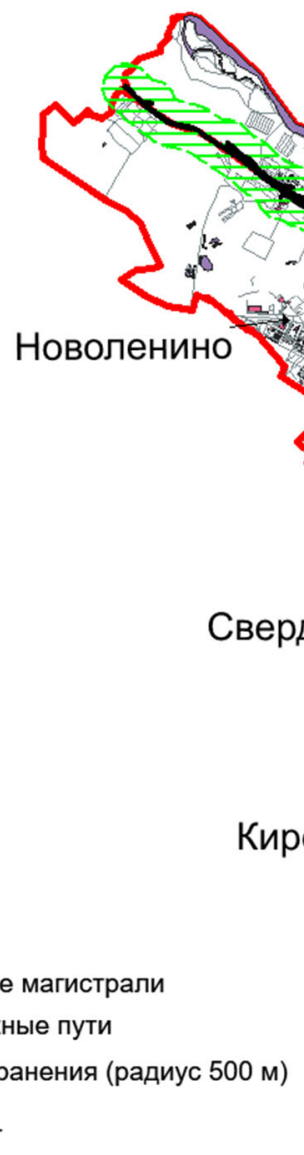

Иркутск-2

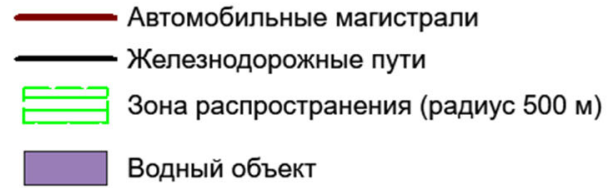

Рис. 3. Территория, подверженная заражению в случае аварии на железнодорожных и автомобильных магистралях.

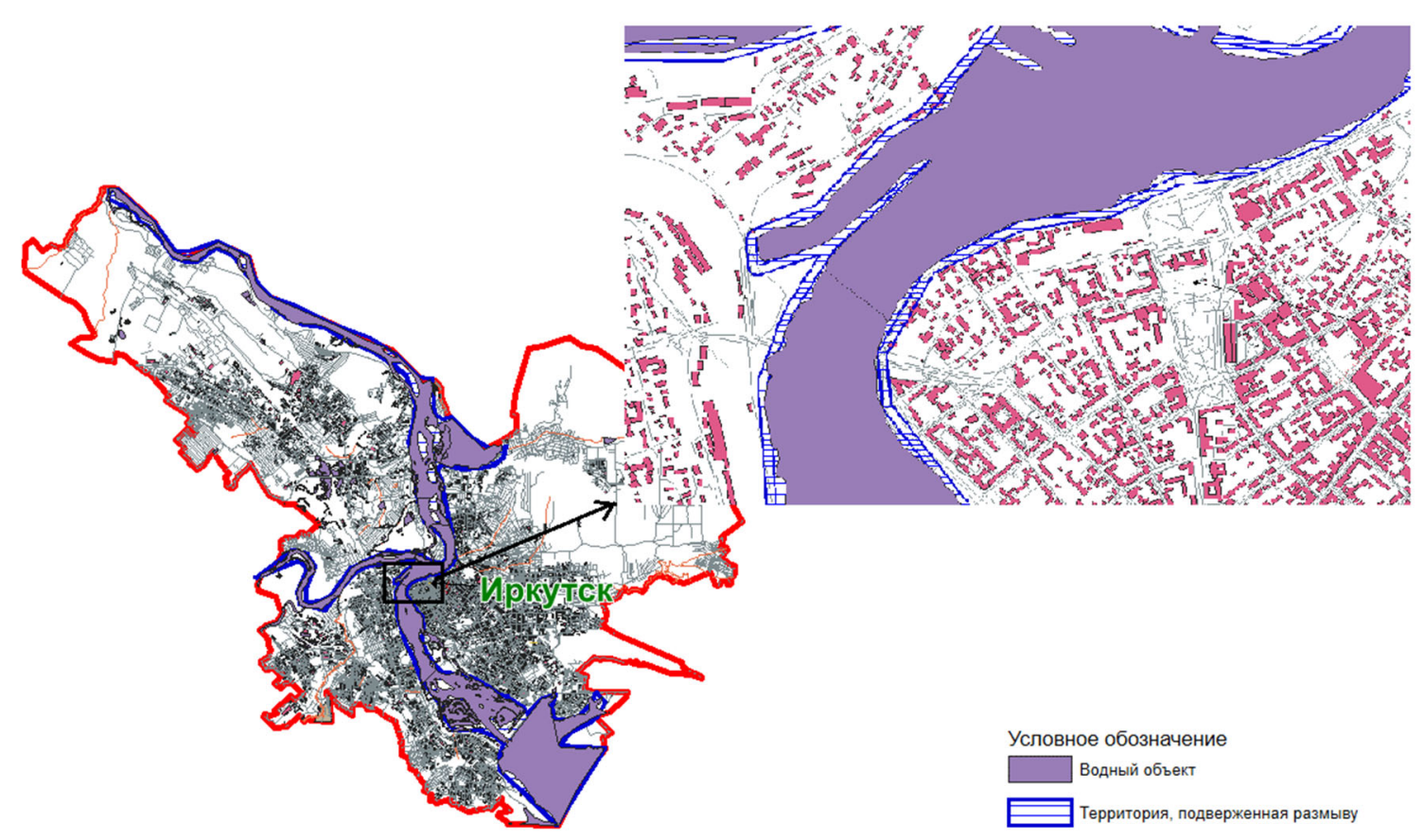

Рис. 4. Прогнозируемый размыв берегов в течении 10 лет 
Таким образом, схема потенциально опасных территорий города выглядит следующим образом (рис. 5):

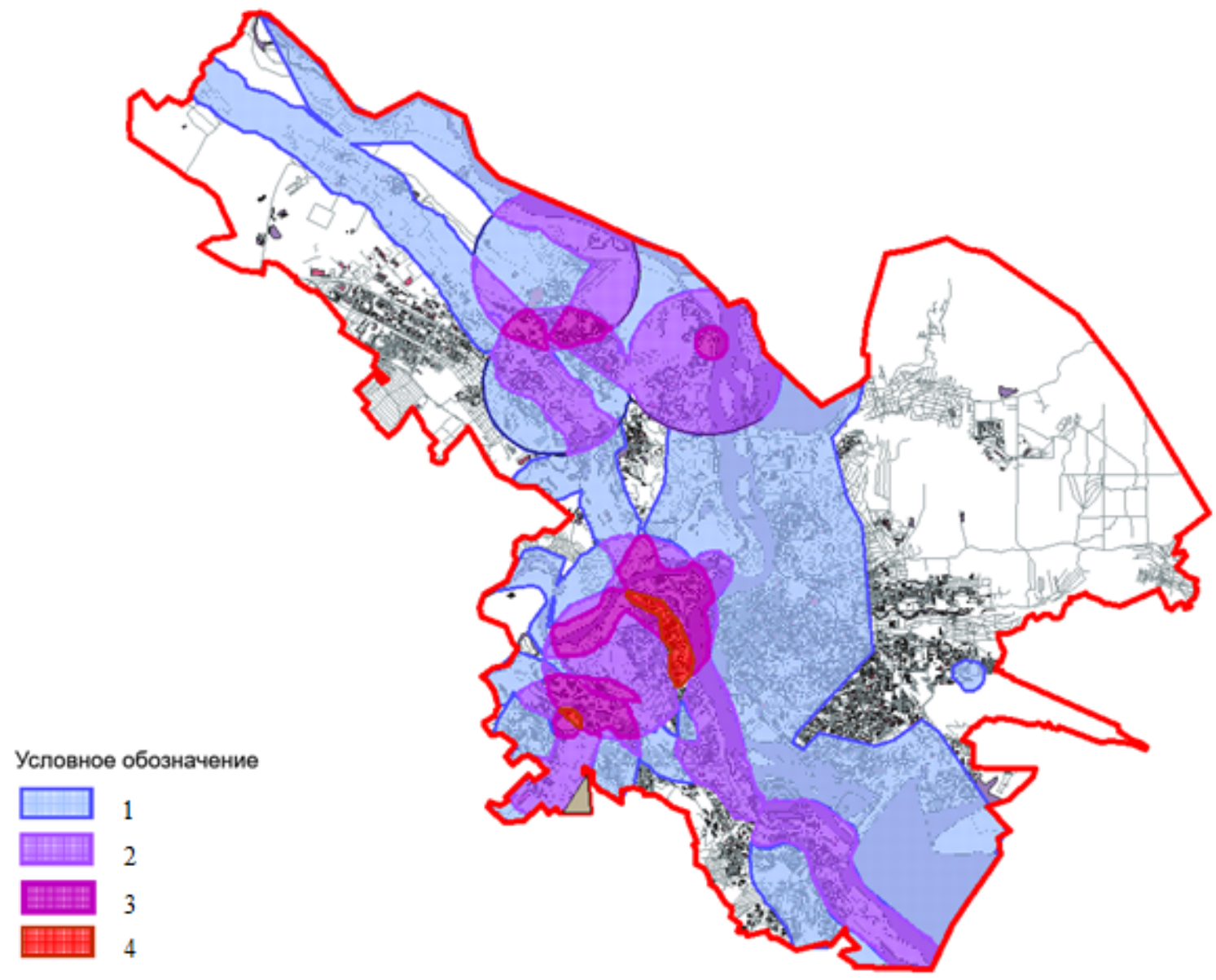

Рис. 5. Схема потенциально опасных территорий города

Схема потенциально опасных территорий города может и должна быть использована при разработке мероприятий по обеспечению безопасности населения, проживающего или находящегося в потенциально опасных зонах. Этим зонам должно уделяться особое внимание при мониторинге загрязнения и при общей работе с территорией на уровне администрации города Иркутск.

\section{БИБЛИОГРАФИЧЕСКИЙ СПИСОК}

1. ГИС для прогнозирования чрезвычайных ситуаций [Электронный ресурс] - Режим доступа: https://studopedia.ru/- Загл. с экрана.

2. Дубровский А.В., Иванов А.Е., Никитин В.Н. Структура программного обеспечения оперативного реагирования и оповещения при возникновении чрезвычайных ситуаций [Электронный ресурс] - Режим доступа: https://cyberleninka.ru/ - Загл. с экрана.

3. Дубровский А.В., Пошивайло А.О. К вопросу влияния степени загрязнения городских земель на кадастровую стоимость недвижимости [Электронный ресурс] - Режим доступа: https://cyberleninka.ru - Загл. с экрана.

4. Иркутск. Факторы риска чрезвычайных ситуаций [Электронный ресурс] - Режим доступа: http://irkipedia.ru/- Загл. с экрана. 
5. Использование геоинформационных систем при мониторинге чрезвычайных ситуаций [Электронный ресурс] - Режим доступа: https://studwood.ru- Загл. с экрана.

6. Карпик, А.П. Анализ природных и техногенных особенностей геопространства чрезвычайной ситуации [Текст] / А.П. Карпик, Э.Л. Ким, А.В. Дубровский / Итерэкспо ГЕОСибирь-2012. VIII Междунар. науч. конгр., 10-20 апреля 2012 г., Новосибирск: Междунар. науч. конф. «Геодезия, геоинформатика, картография, маркшейдерия»: сб. материалов в 3 т. Т.3. - Новосибирск: СГГА, 2012 - С. 171-177.

7. Методика прогнозирования масштабов заражения сильнодействующими ядовитыми веществами при авариях (разрушениях) на химически опасных объектах и транспорте. РД 52.04.253-90 [Текст] - М.: ГосСтандарт, 1991. - 13 с.

8. Наводнение в Иркутской области [Электронный ресурс] - И., 2019. - Режим доступа: https://ru.wikipedia.org/ - Загл. с экрана.

9. О гражданской обороне. Федеральный закон РФ от 12 февраля 1998 г., №28-Ф3 [Текст] - Российская газета, 19 февраля 1998 г., Федеральный выпуск №32-33.

10. О защите населения и территорий от чрезвычайных ситуаций природного и техногенного характера. Федеральный закон РФ от 21 декабря 1994 г., №68-Ф3 [Текст] - Собрании законодательства РФ от 26 декабря 1994 г., № 35 ст. 3648.

11. О порядке организации и ведения гражданской обороны в городе Иркутске. Постановление администрации г.Иркутск от 7.08.2009 года № 031-06-2685/9, с изменениями на 22.09.2017 [Электронный ресурс] - Режим доступа: http://docs.cntd.ru/document/440527324 Загл. с экрана.

12. Об отдельных вопросах по предупреждению чрезвычайных ситуаций на территории иркутской области. Указ губернатора Иркутской области от 17.09.2016 года № 214-уг [Электронный ресурс] - Режим доступа: http://docs.cntd.ru/document/453148266 - Загл. с экрана.

(C) М. Н. Бельи, А. В. Дубровский, 2021 